\title{
JICA's Cooperation in Museum Construction and Capacity Building of Human Resources
}

\author{
Shinichi Yoshihara
}

\begin{abstract}
Japan International Cooperation Agency (JICA), an Incorporated Administrative Agency, assisted developing countries in various fields as the executive agency for Japanese Official Development Assistance (ODA). JICA provides assistance through technical cooperation, loan aid, and grant aid in an integrated manner. The Agency also assists developing countries through dispatch of volunteers, emergency disaster relief, and citizen participatory cooperation. Examples of assistance to museums in Asia are given in this text. However, in comparison with other sectors such as infrastructure, health, and education, projects and training for museum development remain small scale.
\end{abstract}

\section{Preface}

Japan International Cooperation Agency (JICA), an Incorporated Administrative Agency, has been assisting developing countries in various fields as the executing agency of Japanese Official Development Assistance (ODA). JICA provides assistance with three principal schemes, Technical Cooperation, ${ }^{1}$ Loan Aid, ${ }^{2}$ and Grant $\mathrm{Aid}^{3}$ in an integrated manner. In addition to these schemes, JICA also assists developing countries through Dispatch of Volunteers, Emergency Disaster Relief, and Citizen Participatory Cooperation (Fig. 1).

In spite of its smaller scale compared to other sectors such as infrastructure, health, and education, JICA has been continuously implementing projects and training for museum development in developing countries utilizing the three principal schemes and Citizen Participatory Cooperation in cooperation with relevant organizations such as the National Museum of Ethnology.

This paper will explain the purpose of assistance and past achievements, representative projects, and foresight in terms of museums.

\footnotetext{
S. Yoshihara $(\bowtie)$

Japan International Cooperation Agency (JICA), Nibancho Center Building 5-25,

Niban-cho, Chiyoda-ku, Tokyo 102-8012, Japan

e-mail: Yoshihara.Shinichi@jica.go.jp
} 

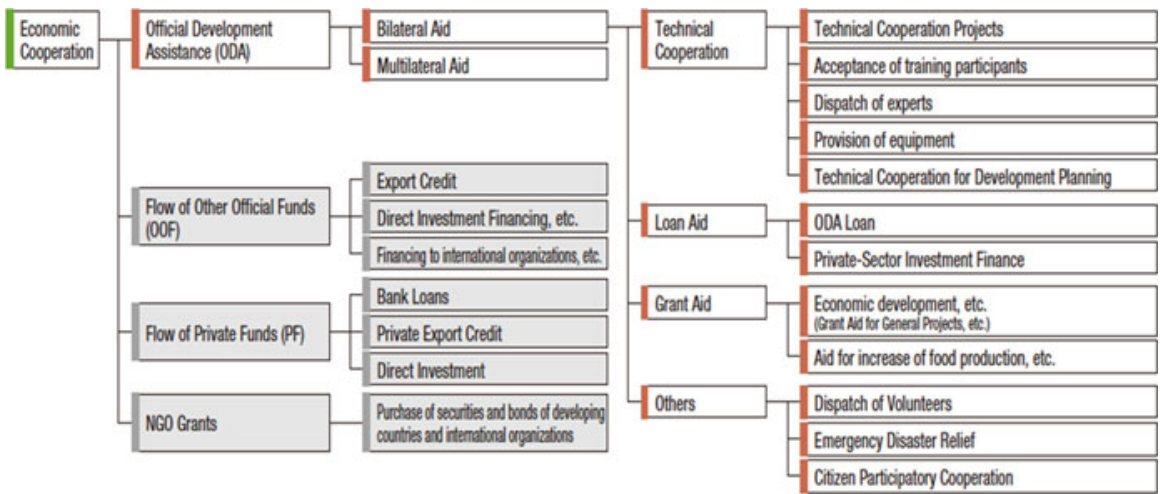

Fig. 1 Economic cooperation and ODA (Source: JICA Annual Report)

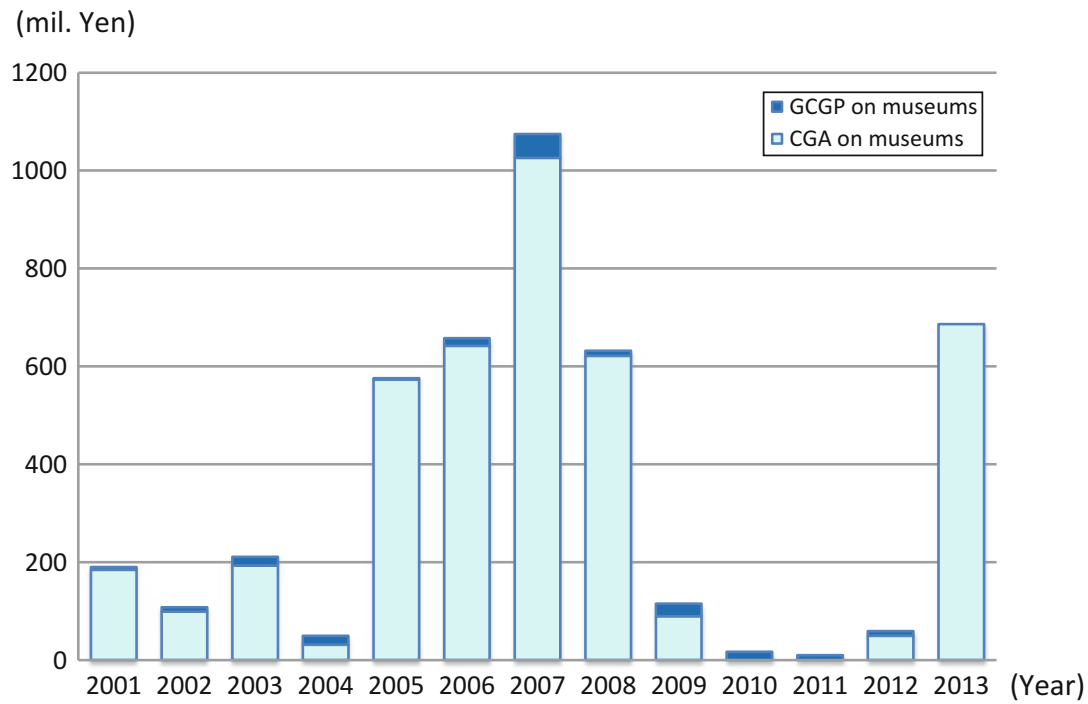

Fig. 2 Assistance to museums through GCGA and GACGP (from 2001 to 2013)

\section{Purpose of Assistance to Museums and Past Achievements}

Assistance to museums by Japanese ODA has mainly been implemented through General Cultural Grant Assistance (GCGA) started from 1975 and Grant Assistance for Cultural Grassroots Projects (GACGP) started from 2000 to contribute to the preservation of cultural heritage and to promote culture and higher education in developing countries. The number of past achievements is shown in Figs. 2, 3, and 4. The highest is Middle East, and Asia, Latin America, and Europe follow. 


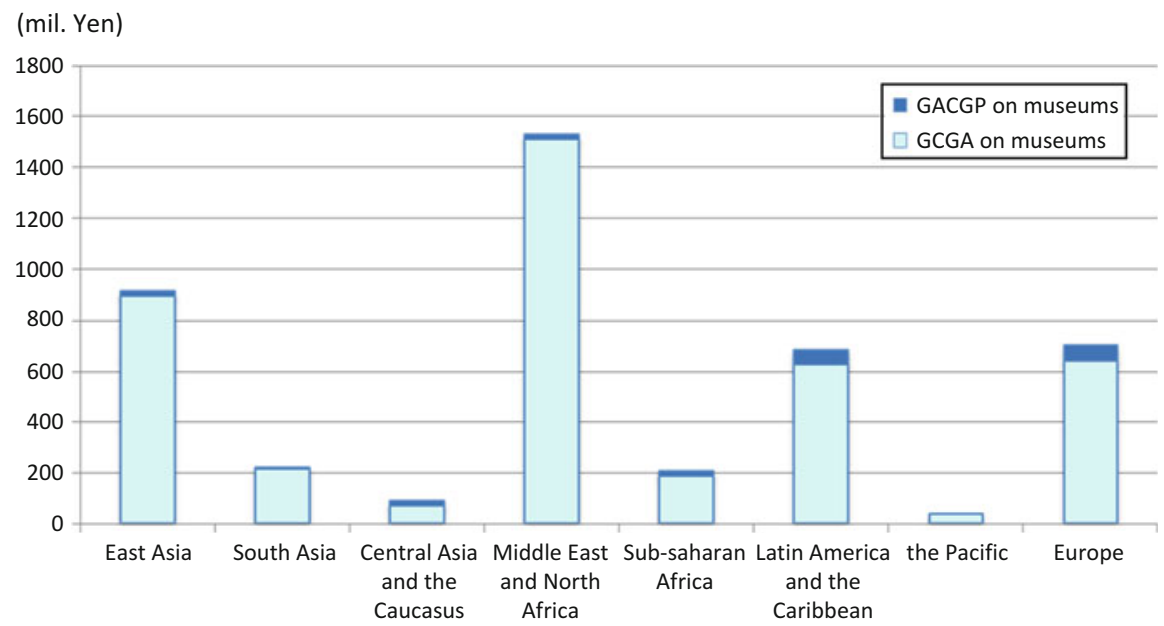

Fig. 3 Assistance to museums through GCGA and GACGP by region

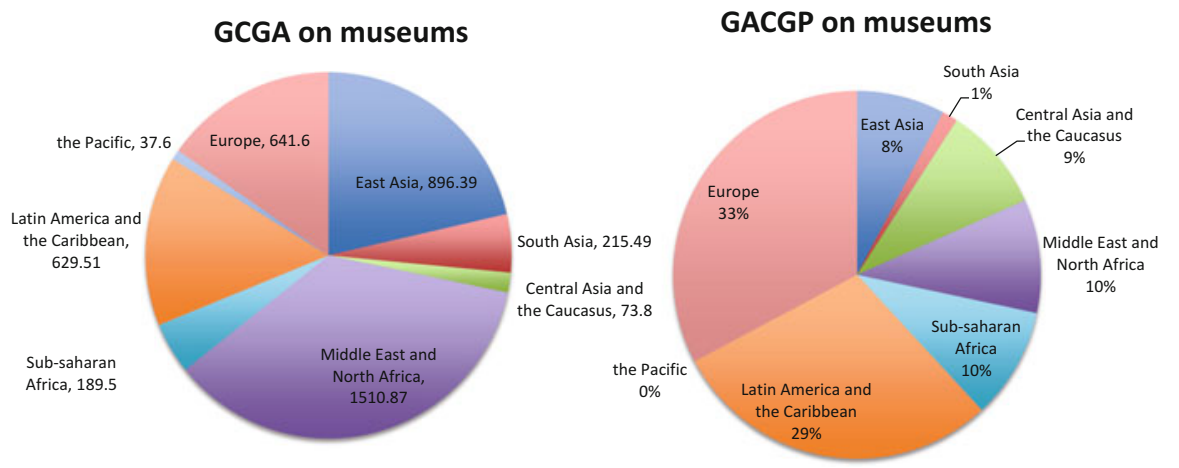

Fig. 4 Assistance to museums through GCGA and GCGP by region (from 2001 to 2013)

In recent years, some projects have been implemented with other schemes such as Technical Cooperation, ODA Loans, and JICA Partnership Programs. They further aim to promote museum-oriented development of a region and/or tourism, contributing to increase in job creation and income level among the local people. 


\section{Representative Projects of Assistance to Museums}

\subsection{Comprehensive Museology (Group- and Region-Focused Training)}

The most comprehensive and historical assistance to museums is the training program "Comprehensive Museology" conducted by the National Museum of Ethnology, Japan (Minpaku) and Lake Biwa Museum. The training course, which has been improving its contents and implementation structure since its commencement in 1994, consists of lectures and practical work for about 3 months.

The objectives of this training program are to provide participants with fundamental knowledge of museum management, as well as to share with them experiences and knowledge of museum activities in Japan. In order to achieve the aim, the program consists of a full set of opportunities for the participants to attend lectures by Japanese experts from various fields, and also to visit museums and cultural sites throughout Japan. Some special training courses, which participants can select according to their own interests, are also offered as options.

In addition to improving the management of museums and professional skills of participants from various countries, the training program also promotes sharing of knowledge and experiences among the participants from developing countries and the Japanese experts who deliver the lectures in the program. A total of 190 people from over 50 countries have completed the program so far and the learning network built up in this training program has expanded to become world-wide as a result of 21-year-long assistance.

\subsection{JICA Partnership Program}

As another approach to meeting the various needs of developing countries, JICA has been financing the "JICA Partnership Program (JPP)," implemented by Japanese museums to utilize their accumulated knowledge and experience in assistance activities for developing countries.

\subsubsection{Community Promotion Featuring Museums and Environmental Improvement around Cultural Assets (JICA Partnership Program, 2008-2011)}

In 2006, Fukuoka Prefecture signed a friendship agreement with Bangkok City, Thailand to strengthen cooperation and exchange information in various fields including the economy, environment, culture, and tourism. With this background, Bangkok requested assistance from Fukuoka with preserving cultural properties and also utilizing them for regional development, which led to Kyusyu National Museum (KNM)'s two consecutive projects under the JICA Partnership Program. 
First of all, KNM conducted training programs from 2008 to 2010 at the Bangkok National Museum (BNM) in Thailand and KNM in Japan, focusing on preservation and utilization of cultural properties, as well as strengthening the contribution of museums to local society.

In the second project, from 2010 to 2011, KNM organized an exhibition at the BNM co-sponsored by the Agency for Cultural Affairs, government of Japan. Through the preparation work for the exhibition, Thai experts worked together with Japanese experts, which led to the creation of an enticing exhibition.

This project contributed to strengthen the relationship between the two museums, and in 2012, KNM entered into an academic exchange agreement with the Fine Arts Department of the Ministry of Culture, Thailand.

\subsubsection{Cambodia-Okinawa "Peace Culture" Museum Cooperation (JICA Partnership Program, 2009-2015)}

The assistance needs of Tuol Sleng Genocide Museum (TSGM) in Cambodia regarding museum operations and management fit the experiences of the Okinawa Prefectural Peace Memorial Museum (OPPMM), which had been considering assisting overseas museums conforming with their establishment concept: passing onto future generations the historic lessons and conveying messages to the peoples of the world. ${ }^{4}$

OPPMM has been implementing two consecutive projects under the JICA Partnership Program.

The first project has started in 2009 and OPPMM provided technical transfer to TSGM in the field of collection, preservation, and exhibition of objects and museums activities on education.

In 2012, OPPMM and TSGM co-organized a special exhibition entitled "Two Peace' Peace Creation Exhibition by Two Peace Museums" at Tuol Sleng Genocide Museum as an achievement of 3-year cooperation. This is a remarkable example of a technical transfer at a museum from a museum that has the same exhibition theme of. Through the continuous cooperation between the two museums, the stage of the project is transitioning from technical transfer of curators to strengthening of museum management in the second project from 2012.

\subsection{Representative Projects in Asia}

\subsubsection{Cooperation to Sigiriya, Sri Lanka (Various Schemes, 2006-2010)}

The Sri Lankan government set the target of developing projects in the cultural and tourism sector as an important national policy, and the Japanese government implemented comprehensive and integrated support through various cooperation schemes. Japan/JICA offered ODA loans for upgrading the access road from the main 
highway to the Sigiriya area and for building facilities such as toilets and a spiral stairway in the Sigiriya Ruins, while it provided assistance for the procurement of display equipment for the Sigiriya Museum by GCGA and dispatched volunteers for promotion of the tourism industry in the surrounding area.

Considering the Sigiriya Museum to be an important tourist-attracting facility in the region, JICA also implemented the Technical Cooperation "Project for the Development of Culture-Oriented Tourism in Sigiriya" that aimed at, and succeeded in, strengthening and enhancing the role of Sigiriya Museum in tourism activities, leading to tourism development in the region by providing technical assistance for, for example, the lectures on management of the museum, making a tourism promotion plan, and tour guide training.

\subsection{Representative Projects in the Middle East}

\subsubsection{Tourism Promotion Through Museum Activities, Jordan (Technical Cooperation, 2004-2007)}

Tourism is one of the major industries in Jordan, and Japan/JICA has been assisting the promotion of this sector through development of facilities and technical transfer. JICA carried out a study on "National Tourism Development Strategy and Policy" between 1994 and 1996, and proposed future projects including the establishment of four major museums in Jordan. Based on this study result, Japan offered an ODA loan for promotion of tourism by construction of road and tourism facilities such as museums in 1999.

Parallel with this, JICA dispatched volunteers and short-term experts as well as accepting Jordanians for training in Japan. In the course of cooperation, the needs for improving museum management were ascertained.

In this context, JICA implemented the Technical Cooperation Project "Tourism Promotion through Museum Activities" providing capacity development assistance for museum management, collection, and display, of objects to the four model museums built by the Japanese ODA loan: National Museum, Karak Archaeological Museum, Dead Sea Museum, and Historic Old Salt Museum. As a result of this project, counterparts became able to make long-term plans, produce a newspaper, and conduct educational and local activities.

The cooperation with Minpaku in this project made it successful and had a positive impact on all target museums.

\subsubsection{Project for the Conservation Center in the Grand Egyptian Museum (Technical Assistance Related to Japanese ODA Loan, 2008-2016)}

With the assistance of the National Research Institute for Cultural Properties, Tokyo, JICA has been implementing a project providing technical transfer such as Preventive Conservation, Conservation, Conservation Science, and also management to the 
Grand Egyptian Museum Conservation Center (GEM-CC) affiliated with the Grand Egyptian Museum, which is currently under construction with support of a Japanese ODA loan.

In Phase 1 (2008-2011), building an accurate database as well as a department in charge of it was the main activity. In addition to this, JICA also conducted several training programs that were of high priority for GEM-CC.

In Phase 2 (2008-2016), JICA has planned 25 different kinds of training. A total of 85 training programs were conducted and 1036 GEM-CC staff members participated in total by December 2014.

\section{Foresight}

As mentioned above, Japan has been supporting museums of various countries through ODA. It is notable that JICA has the potential to connect overseas and Japanese museums. The experiences, knowledge, and networks gained through implementation of projects are expected to be utilized for further development of museums that promote the attractiveness of each region around the world.

\section{Notes}

1. Technical Cooperation draws on Japan's technology, knowhow, and experience in nurturing the human resources who will promote socioeconomic development in developing countries.

2. Loan Aid supports the efforts of developing countries to advance by providing these nations with the capital necessary for development under long-term and substantially lower interest rates than commercial rates.

3. Grant Aid, which is an assistance method that provides necessary funds to promote socioeconomic development, is financial cooperation with developing countries with no obligation for repayment.

4. Source: Website of OPPMM.

Open Access This chapter is distributed under the terms of the Creative Commons AttributionNonCommercial 4.0 International License (http://creativecommons.org/licenses/by-nc/4.0/), which permits any noncommercial use, duplication, adaptation, distribution and reproduction in any medium or format, as long as you give appropriate credit to the original author(s) and the source, provide a link to the Creative Commons license and indicate if changes were made.

The images or other third party material in this chapter are included in the work's Creative Commons license, unless indicated otherwise in the credit line; if such material is not included in the work's Creative Commons license and the respective action is not permitted by statutory regulation, users will need to obtain permission from the license holder to duplicate, adapt or reproduce the material. 